\title{
Treatment Approaches for First Episode and Early-Phase Schizophrenia in Adolescents and Young Adults: A Delphi Consensus Report from Europe
}

\begin{abstract}
Christoph U Correll $\mathbb{1}^{1-3}$, Paolo Fusar-Poli ${ }^{4-6}$, Stefan Leucht ${ }^{7}$, Anne Karow ${ }^{8}$, Nadja Maric $\mathbb{D}^{9}$, Carmen Moreno ${ }^{10}$, Merete Nordentoft ${ }^{11}$, Andrea Raballo ${ }^{12,13}$

'Department of Child and Adolescent Psychiatry, Charité Universitätsmedizin, Berlin, Germany; ${ }^{2}$ Department of Psychiatry and Molecular Medicine, Zucker School of Medicine at Hofstra/Northwell, Hempstead, NY, USA; ${ }^{3}$ Department of Psychiatry, The Zucker Hillside Hospital, Glen Oaks, NY, USA; ${ }^{4}$ Early Psychosis: Interventions and Clinical-detection (EPIC) Lab, Department of Psychosis Studies, Institute of Psychiatry, Psychology \& Neuroscience, King's College London, London, UK; ${ }^{5}$ OASIS service, South London and Maudsley NHS Foundation Trust, London, UK; ${ }^{6}$ Department of Brain and Behavioural Sciences, University of Pavia, Pavia, Italy; ${ }^{7}$ Section Evidence-Based Medicine in Psychiatry and Psychotherapy, Department of Psychiatry and Psychotherapy, Technical University of Munich, School of Medicine, Munich, Germany; ${ }^{8}$ Department of Psychiatry and Psychotherapy, University Medical Centre Hamburg-Eppendorf, Hamburg, Germany; ${ }^{9}$ Faculty of Medicine, University of Belgrade and Institute of Mental Health, Belgrade, Serbia; ${ }^{10}$ Department of Child and Adolescent Psychiatry, Institute of Psychiatry and Mental Health, Hospital General Universitario Gregorio Marañón, School of Medicine, Universidad Complutense, liSGM, CIBERSAM, Madrid, Spain; "'CORE-Copenhagen Research Centre for Mental Health, Mental Health Services in the Capital Region, Department of Clinical Medicine, Faculty of Health Sciences, University of Copenhagen, Copenhagen, Denmark; ${ }^{12}$ Section of Psychiatry, Clinical Psychology and Rehabilitation, Department of Medicine, University of Perugia, Perugia, Italy; ${ }^{13}$ Centre for Translational, Phenomenological and Developmental Psychopathology (CTPDP), Perugia University Hospital, Perugia, Italy
\end{abstract}

Correspondence: Christoph U Correll, Department of Child and Adolescent Psychiatry, Charité Universitätsmedizin, Augustenburger Platz I, Berlin, 13353, Germany, Tel +49-30-450-566202, Fax +49-30-450-56692I, Email christoph.correll@charite.de

Purpose: Although first-episode psychosis (FEP) in youth, particularly early-onset schizophrenia (EOS), is managed similarly to adult-onset schizophrenia, few antipsychotics are approved for people aged 13-18 years. We aimed to explore areas of uncertainty in EOS management and provide evidence-based recommendations to mental health specialists. We used the Delphi methodology to gain knowledge in areas lacking evidence-based strategies. This standardized methodology consists of the development of a questionnaire by content experts, which is then submitted to a broader panel of professionals (panelists) to survey their level of agreement on the topics proposed.

Materials and Methods: The developed questionnaire covered patient management from diagnosis to maintenance treatment and was administered to a broader panel of specialists across Europe. Based on an analysis of responses received in this first round, the items that needed further insight were submitted to the panel for a second round and then reanalysed.

Results: An initial set of 90 items was developed; in round I, consensus was reached for 83/90 items (92\%), while it was reached for $7 / 11$ (64\%) of the items sent out for rerating in round II. Feedback for rounds I and II was obtained from 54/92 and 48/54 approached experts, respectively. There was broad agreement on diagnostic standards, multimodal approaches and focus on adverse events, but uncertainty in terms of pharmacological strategies (including clozapine) in case of failure and antipsychotic dosing in younger patients. Conclusion: Despite knowledge about diagnostic clues and integrated management of EOS, this study highlights the lack of standardization in treating EOS, with safety arguments having a major role in the decision-making process. Targeted clinical trials and systematic dissemination across Europe of current scientific evidence on the value of early intervention services is hoped to contribute to standardized and improved quality care for patients with early-phase psychosis and schizophrenia.

Keywords: schizophrenia, Delphi, psychosis, early onset, management

\section{Introduction}

Sharing many overlapping characteristics with adult-onset schizophrenia, first-episode psychosis (FEP)/early-onset schizophrenia (EOS), ie, onset prior to 18 years of age, is a relatively rare form of schizophrenia. ${ }^{1-9}$ According to a recent meta-analysis, $2 \%$ of people with schizophrenia had their onset prior to age 14 (schizophrenia-spectrum disorders $=3 \%$ ) and $8 \%$ prior to age 18 (schizophrenia-spectrum disorders $=12 \%$ ). ${ }^{10}$ Furthermore, compared to

Received: 3 November 2021 Accepted: 13 January 2022

Published: 9 February 2022 
adult-onset schizophrenia, EOS is characterised by a longer duration of untreated psychosis, more pronounced negative and cognitive symptoms since onset, greater long-term disability and less favourable prognosis. ${ }^{1-3,11,12}$

Compared to adult-onset schizophrenia, the diagnostic process is complex given the preceding psychopathology (also termed the clinical high-risk stage), ${ }^{13,14}$ many ongoing physiological changes and peak time emergence of other mental disorders during this developmental age, ${ }^{10}$ when disruption of early neurodevelopmental patterns can occur, particularly during the prenatal/perinatal period and adolescence. ${ }^{15-21}$ Genetic susceptibility enhanced by environmental or chemical factors and traumatic events appears to trigger an abnormal development of some brain regions, resulting in alteration of white matter, greater loss of grey matter, excess synaptic pruning, and dysregulation of stress signalling pathways. ${ }^{16-19,22}$ The differentiation of impairments in brain connectivity depends on the developmental period during which these triggers act, influencing disease onset and trajectory. Many of the implicated risk factors ${ }^{23}$ and symptoms peak between the age of 13-18 years ${ }^{24}$ and may overlap with those of other disorders, such as autism spectrum and other conditions, ${ }^{16,17,25,26}$ pointing to schizophrenia as a cluster of disease entities with multiple causes. ${ }^{26,27}$

Accordingly, the management of FEP/EOS currently includes multimodal approaches integrating pharmacological and nonpharmacological interventions (psychosocial, cognitive-behavioural therapy, etc.), ${ }^{28,29}$ which can improve the disease course and long-term outcomes compared to either of these approaches alone., ${ }^{2,4,28,29}$ Pharmacological interventions available for EOS mostly rely on the same antipsychotic agents used in adultonset schizophrenia. ${ }^{11,30-33}$ Antipsychotics primarily consist of dopamine D2 receptor antagonists (first-generation antipsychotics, FGAs) and serotonin-dopamine antagonists/partial agonists (second-generation antipsychotics, SGAs). Different effects on these and other receptors are also responsible for different side effects, including weight gain, lipid abnormalities, glucose abnormalities, prolactin elevation, sedation, extrapyramidal effects and akathisia. ${ }^{30,34}$

SGAs approved in Europe for the treatment of schizophrenia include aripiprazole, asenapine, brexpiprazole, cariprazine, lurasidone, olanzapine, paliperidone, quetiapine, risperidone, and ziprasidone, as well as clozapine for treatmentresistant schizophrenia. ${ }^{35}$ Of these SGAs, only three have specific European Medicine Agency (EMA) approval for use before 18 years of age: aripiprazole and paliperidone approved for people aged 15-17 years old, and lurasidone approved for use at 13-17 years of age. ${ }^{11,30-32}$ To date, in adults and youth, there is no direct evidence of higher efficacy of any specific antipsychotic over another, except for clozapine. ${ }^{31-33,36,37}$ A recent network meta-analysis, ${ }^{33}$ which specifically addressed the use of non-clozapine antipsychotics in adolescents with EOS, concluded that all agents evaluated, with the exception of ziprasidone and asenapine, had comparable effectiveness in terms of PANSS total symptom change and other outcomes and that adverse reaction/safety profiles were consistent with the findings in adult patients. The study, however, did not include the antipsychotic lurasidone, which has recently been approved by EMA for treatment from the age of 13 years old. ${ }^{31}$ The data available to date demonstrate lurasidone similar efficacy to other oral SGAs but with less weight gain and a lower risk of all-cause discontinuation. ${ }^{31}$

In reference to this latter aspect, children and adolescents seem more susceptible to acute extrapyramidal side effects, sedation, withdrawal dyskinesia, hyperprolactinemia, weight gain and metabolic abnormalities than adults..$^{30,38,39}$ Thus, in principle, the choice of an agent should be driven by its tolerability profile. ${ }^{3}$

In any case, because adolescence is a critical stage of development, early interventions can increase the possibility of recovering and pursuing psychological wellbeing. Specifically, because EOS dramatically interferes with age-related developmental milestones, such as independent living, vocational training and social integration, early intervention is paramount in preventing cumulative disability for the patient as well as an escalation of costs for society. ${ }^{11,16,30,38}$

To date, recommendations for the management of EOS mirror those for adults and are quite heterogeneous, with differences stemming from local health care policies, organization of medical services, treatment schools, economic resources, and cultural settings. ${ }^{40,41}$

The aim of this work was to explore any critical areas in the management of FEP/EOS by means of a computer-based survey involving European specialists with expertise in paediatric schizophrenia to provide guidance to clinicians on the best, evidence-based management strategies for EOS. 


\section{Materials and Methods \\ Study Design and Scope}

We employed the Delphi methodology, which is widely used as an exploratory tool to gain knowledge in areas that are difficult to cover by means of evidence-based strategies. ${ }^{42,43}$ In general, the process begins with an open-ended research question being discussed among a group of content experts (Steering Committee) through an iterative process involving the sharing of opinions, professional experience, and scientific evidence. The process (question sourcing) leads to the development of a list of statements/items (Delphi questionnaire), which is then submitted to a broader panel of professionals (panellists) to survey their level of agreement on the topics proposed (Delphi rounds of consensus). ${ }^{42,43}$ The process is completed when feedback converges, providing no new elements of insight (reaching saturation).

The present study, which took place from November 2020 to May 2021, addressed the unmet needs in the management of FEP/EOS, asking which were the areas needing priority attention. The Steering Committee was composed of 5 adult psychiatrists with a focus on first-episode and young adults with psychotic disorders, 1 child and adolescent psychiatrist and 2 experts in both child/adolescent and adult psychiatry. Professionals invited to discuss the topic were chosen among a group of internationally recognized experts in the treatment of child and adult psychiatry and/or schizophrenia with experience in guidelines committees and clinical research who were actively practicing in Europe.

\section{Development of the Delphi Questionnaire}

This first step of question sourcing served to collect an initial pool of feedback on areas/domains that the experts considered most critical based on their clinical practice. Comments were then analysed and coded into themes, grouping subsets of related items of enquiry. The organization of themes and items into a coherent and meaningful set of statements for the Delphi questionnaire was further informed by a literature review on the management of FEP/EOS in European countries (reviews, trials, guidelines). The first draft of the Delphi Questionnaire was submitted to the members of the Steering Committee for critical appraisal and improvement of the draft to ensure that items were relevant to the research question, were clearly worded and did not overlap with previous items.

The second draft was then submitted for validation to a restricted group of colleagues. Once the final version of the questionnaire was approved by the Steering Committee, the document was placed on a dedicated online platform and submitted to a list of participants. The candidate panelists were selected by members of the Steering Committee who provided contacts of clinical specialists in the field of child and adolescent and adult psychiatry (psychiatrists, psychologist, neuropsychiatrists) practicing in Europe with $\geq 4$ years of clinical experience in the treatment of FEP/ EOS and who considered themselves "expert clinicians" in the use of antipsychotics for this indication.

\section{Delphi Rounds of Approval}

Participants were invited to participate in the survey via e-mail. Replies from the first round were collected in an anonymous fashion. Levels of agreement/disagreement for each statement were captured by a 5 -point Likert scale $(1=$ strongly disagree, $2=$ disagree, $3=$ agree, $4=$ more than agree, $5=$ strongly agree). Consensus was predefined as $>66 \%$ of the panel agreeing/disagreeing with any given item.

All responses from the first round were reviewed by the Steering Committee and commented on during a virtual roundtable discussion. Any items that did not yield a clear-cut agreement, were in contrast with the current scientific evidence (statement 18.4), or generated new areas of enquiry (statement 2.7, 18.1, 18.2, 18.3, 18.5) were discussed by the Steering Committee in an iterative process. To gain insight into the opinions and experience of the panellists about these themes with unclear results, another set of statements was sent out to the participants for a second round of feedback. In the invitation to the second Delphi round, panellists received an overview of the results from the first round and a selection of recent evidence on the topics addressed by the statements included in the second round according to standard Delphi methodology. ${ }^{42,43}$

The study was based on a survey that does not involve the participation of human subjects nor patient data management. Consequently, this study did not require ethical approval. All experts involved in the Delphi survey were 
informed of the study's objectives and the possibility of publishing the results in a peer-reviewed article. The participation was voluntary. The panelists expressed their consent to participate in the survey after logging into the secure online survey platform by actively clicking on the appropriate consent box.

\section{Results}

The Delphi process involved two rounds of questioning to reach consensus (Figure 1). The questionnaire for Round I covered 5 main topics/domains spanning the patient pathway from diagnosis to maintenance treatment, namely: timely detection of signs of FEP/EOS and formal diagnosis, access to the care of individuals with symptoms and signs of FEP or EOS, treatments and outcomes, nonpharmacological treatments, strategic management, and clinical practice/scientific evidence. Overall, the questionnaire featured 18 main statements, each developed into one or more items for a total of 89 items (see Appendix 1). All items asked panellists for their agreement on what they believed should be standard practice in their culture/treatment setting.

Of 92 professionals contacted to participate in the survey, 10 contacts were excluded due to e-mail delivery issues, and 9 questionnaires were incomplete upon the closing date and, therefore, discarded. For the first round, complete responses were gathered from 54 mental health practitioners (74\% of all professionals contacted), equally balanced between males (46\%) and females (54\%), from eight different European countries (1 from Bosnia and Herzegovina, 2 from Denmark, 13 from Germany, 12 from Italy, 1 from Montenegro, 7 from Serbia, 10 from Spain, 7 from UK). In the second round, responses were gathered from all but 6 respondents from the first round.

Among the 90 items, a consensus was reached for 83 (92\%) items ( 80 with a positive consensus, 3 with a negative consensus, ie, 7.1, 18.6, 18.8), while only 7 items $(2.7,4.4,7.3,7.5,12.2,18.1,18.4)$ failed to reach the $>66 \%$ threshold for establishing consensus. Among the 80 items that gained positive consensus, the agreement was strong (scores 4 and 5 more frequent than 3) for 59 (74\%) statements (Figure 2). On the other hand, among the 3 items that gained a negative consensus, the agreement was strong (score 1 more frequent than 2) for none.

Based on the responses from the first round, the Steering Committee decided that 3 of the 18 main statements required rerating (Figure 1), leading to 4 new items (19.1-19.4) and 7 edited items (S. 2.7 and 18.1-18.6). Aside from one question on the diagnostic process (item 2.7), all other items required further insight concerning treatment aspects. Of the 11 items submitted to the panellists for Round II, consensus (either positive or negative) was reached for 7 items (64\%), leaving 4 statements with no strong consensus position (ie, 18.2, 18.3, 19.1, 19.2) (Figure 3).

\section{Timely Detection and Access to Care}

In general, panellists broadly acknowledged the need for repeated evaluations to reach the diagnosis of FEP/EOS (S. 1) and the benefit of rapid service engagement towards better future outcomes (S. 3).

Regarding the diagnostic tests to be considered gold standards in a differential diagnosis (S. 2.1-2.11), preferences were given (in order from highest to lowest agreement) to history taking, cognitive assessment, history of substance abuse, thorough physical assessment and laboratory work, urine toxicology, diagnosis of EOS with validated tools, using magnetic resonance brain imaging, and electroencephalography (70\%). Conversely, lumbar puncture (S. 2.7) was not considered the gold standard test (only 35\% in favour in the first round), unless there was clinical evidence of neurological abnormality ( $85 \%$ agreed in the second round).

As to obstacles to timely detection (S. 4.1-4.11), panellists mainly attributed this to patients and/or family members and their lack of awareness of mental health issues or the need for medical referral. Many (81\%) also attributed the delay to be linked to missed recognition by health care professionals (S. 4.8). The lack of affordable services (S. 4.4) received mixed responses without a consensus.

Increasing education/awareness through mental health literacy campaigns (S. 5) was considered appropriate for all groups, from general practitioners and health professionals to the general population.

\section{Treatments and Outcomes}

Panellists strongly agreed that young patients should receive both pharmacological and specific evidence-based psychosocial interventions (S. 6) and be involved in adherence-enhancing strategies (S. 11). Despite strong agreement on the 


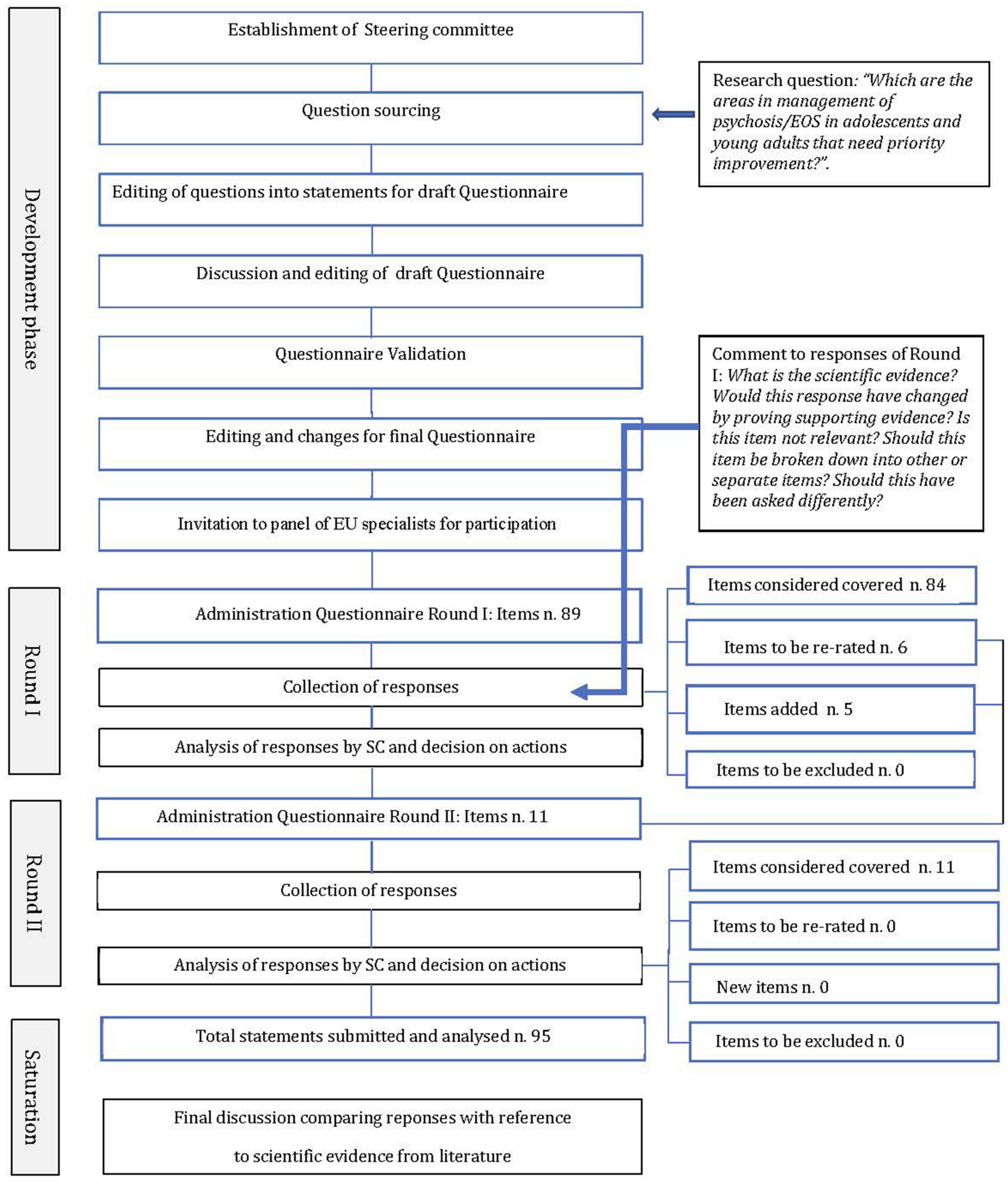

Figure I Delphi study flowchart.

higher sensitivity of younger patients to medication adverse effects (S. 7.2) there was mixed feedback regarding whether young patients required lower antipsychotic doses than adults (S. 7.3). Likewise, most panellists tended to disagree (without reaching a clear-cut consensus) that adolescents/young adults should only be treated with antipsychotics that are licenced for that age group (S. 7.5.). 


\section{A Delphi Round I: Levels of agreement and distribution of responses- Topic 1}

(1) Diagnosis of psychosis and early-onset schizophrenia (EOS) often requires repeated evaluations, due to non-specific symptoms and signs and potential patient reluctance to disclose symptoms.

\section{Disagreement}

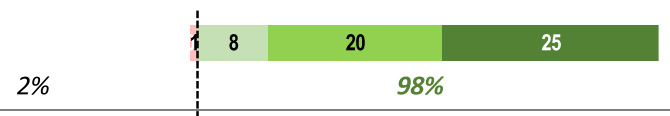

(2) The gold standard for diagnosing primary psychosis or EOS should include:

(2.1) Detailed history-taking of both patient and family.

(2.2) Assessment of cognitive problems.

(2.3) Thorough physical assessment, routine laboratory testing

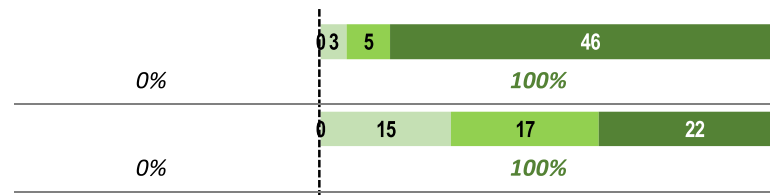

$9 \%$

(2.4) Ruling out substance-induced psychosis by history.

(2.5) Confirmation of EOS using validated clinical classification criteria.

(2.6) Confirmation of EOS using validated interviews/tools.

(2.7) Perform a lumbar puncture.

(2.8) Perform brain imaging (MRI, CT).

(2.9) Perform urine toxicology.

(2.1) Detailed history-taking of both patient and family.

(2.11) Screen for autoimmune encephalitis.

(3) Shortening of the duration from first psychotic symptoms to service engagement improves outcomes.

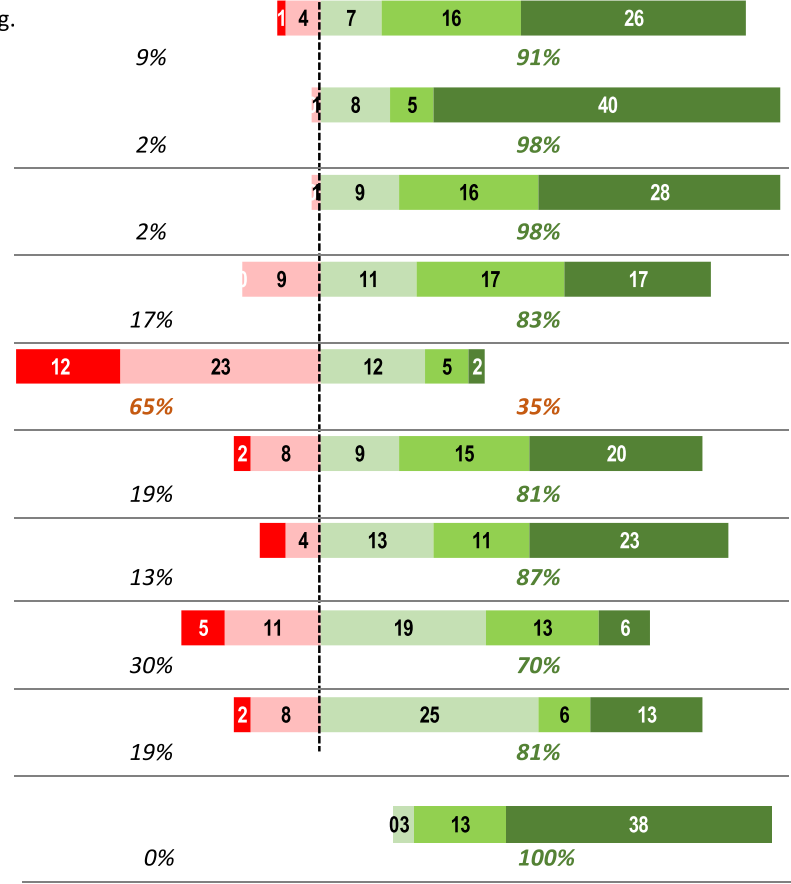

(4) A common obstacle to the timely detection of psychosis/early-onset schizophrenia is:

(4.1) The individual's and/or family's delay in recognizing symptoms and signs of psychosis.

(4.2) The individual's and/or family's delay in seeking care for psychosis

(4.3) The lack of readily accessible services.

(4.4) The lack of affordable services.

(4.5) Stigma associated with psychiatric illness and/or care.

\begin{tabular}{cccccccc} 
& & & 3 & 10 & \multicolumn{2}{c}{21} & 20 \\
\hline $6 \%$ & & & & $94 \%$ & \\
\hline $2 \%$ & & & 1 & 14 & \multicolumn{2}{c}{18} & 21 \\
\hline & & & & $98 \%$ & & \\
\hline $2 \%$ & 4 & 10 & 11 & 16 & 13 & \\
\hline
\end{tabular}

(4.6) The overlap of the symptoms of other psychiatric disorders with psychosis.

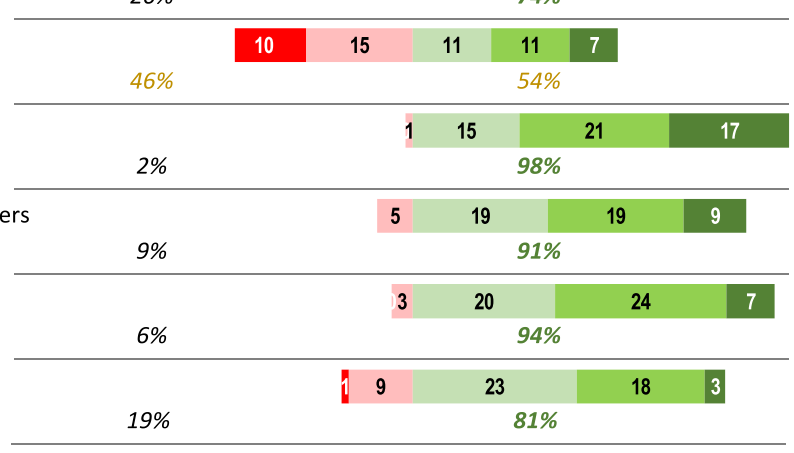

Figure 2 Continued. 


\section{B Delphi Round I: Levels of agreement and distribution of responses- Topic 2}

(5) To improve access to care and timely recognition and treatment of psychosis/EOS the following group should receive education through mental health literacy campaigns:

Disagreement

Agreement

(5.1) Adolescents and young adults (school, college).

(5.2) School/college personnel.

(5.3) General practitioners/family doctors/pediatricians.

(5.4) Other healthcare professionals.

(5.5) Public services personnel (e.g., police, first-line rescue workers, social services)

(5.6) General population.

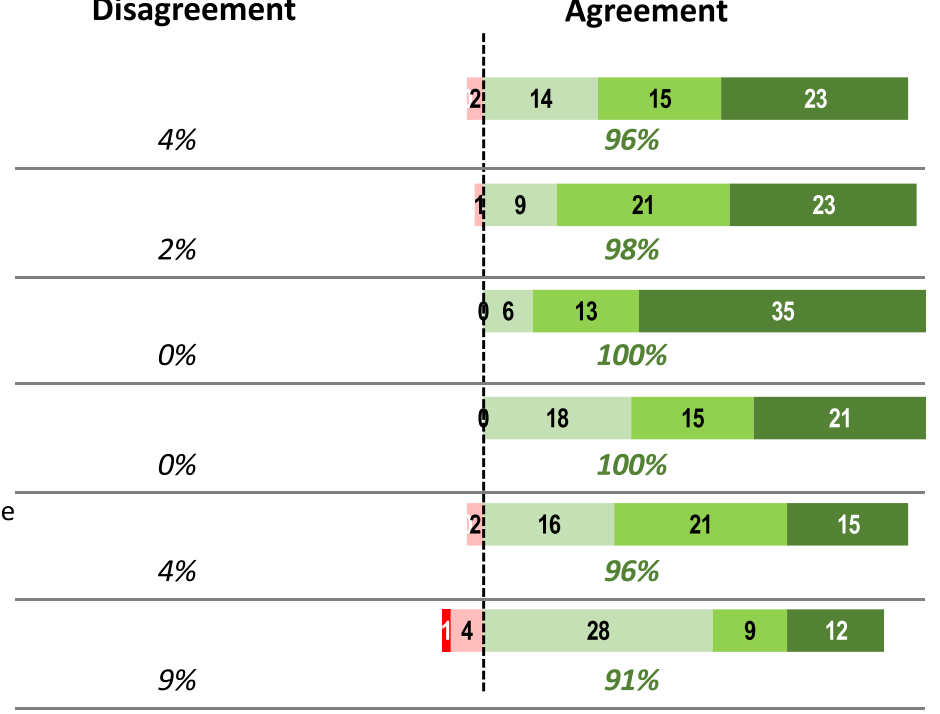

Figure 2 Continued.

Regarding the need for periodic evaluations of side effects (S. 9) and metabolic parameters throughout pharmacological treatment (S. 7.6), there was broad agreement on the timing of evaluations. However, $13 \%$ did not agree on an ECG evaluation upon reaching the steady dose of antipsychotics.

\section{Nonpharmacological Interventions}

Among the most frequently employed nonpharmacological interventions, almost all interventions listed (S. 12.1 to 12.11) received broad agreement from panellists, with the preference (in order of level of agreement achieved) for social training skills and supported employment (100\%), targeting negative and cognitive symptoms and physical activity (98\%), occupational therapy (91\%), assertive outreach (87\%), and art/music therapy. Psychodynamic therapy was the only intervention not considered useful (negative consensus).

While panellists agreed that intervention services for adolescents/young adults should be connected into an integrated network and on having dedicated transitional age services (S. 15), no clear recommendation emerged regarding the duration of early intervention services (S. 14.1-14.5), although most agreed on a timeframe between 2 and 5 years.

\section{Clinical Practice/Scientific Evidence}

Regarding the goals of antipsychotic treatment (S. 16.1-16.6), none emerged as clearly more important than the others, with all being ranked as "the most important".

Regarding treatment strategies adopted in cases of nonresponse and on how long to wait after treatment failure (S. 18.1-18.3), most panellists agreed on waiting 4 weeks for a response, with some even waiting 6 weeks before considering a change in therapy, whereas the 2-week waiting period (S. 18.1) did not yield a consensus either in favour or against. Therefore, the statement was further explored in Round II with the items edited (Figure 3), splitting the waiting period into one, two, three, four and six weeks. In Round II, the vast majority (94\%) of panellists shifted opinions towards waiting at least one week after nonresponse before switching antipsychotics.

Panellists were markedly more inclined to switch to another antipsychotic monotherapy (S. 18.5) than adding a second antipsychotic (S. 18.6). Regarding the switch to clozapine (S.18.8-18.10), very few (15\%) agreed to switch 


\section{Delphi Round I: Levels of agreement and distribution of responses- Topic 3}

Disagreement

(6) As part of standard care, adolescents/young adults with psychosis/EOS should receive both pharmacological and specific, evidence-based psycho-social interventions.
Agreement

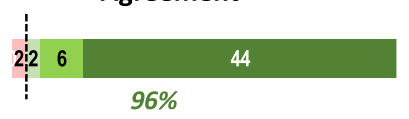

(7) Compared to the management of adults with multi-episode psychosis, management of adolescents/young adults with psychosis/EOS differs in that:

(7.1) Antipsychotics should be initiated in adolescents/young adults only if initial psycho-therapeutic interventions are not effective.

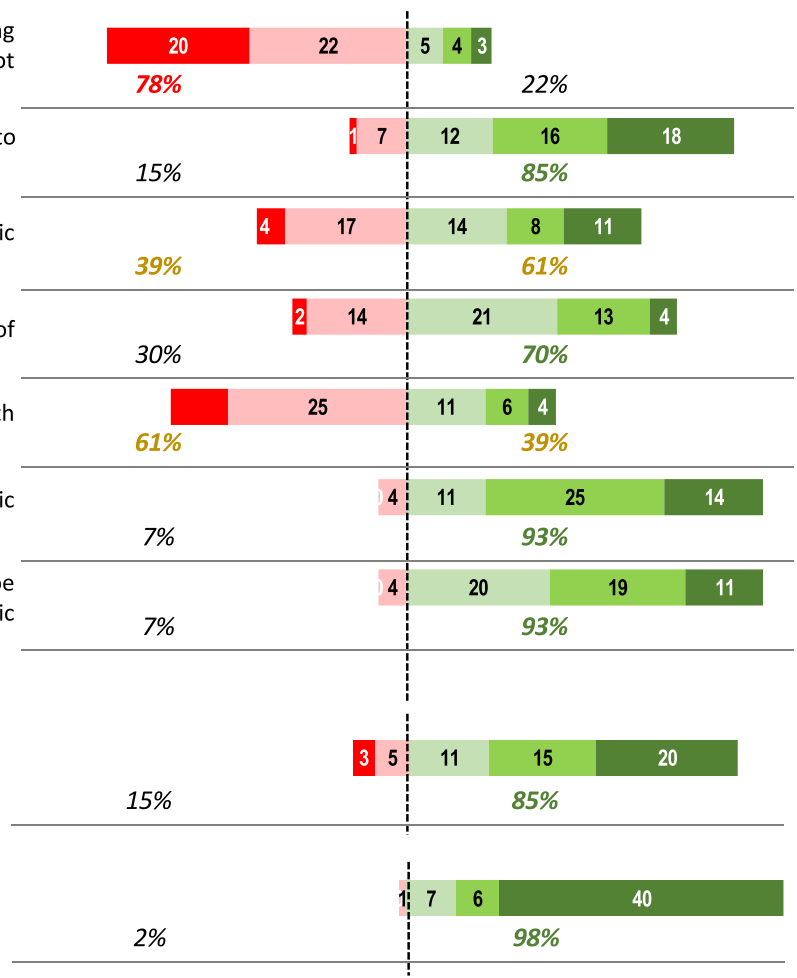

(9) Adolescents/young adults pharmacologically treated for psychosis or EOS should be monitored at each visit for clinical side effects.

(7.2) Adolescents/young adults are more sensitive to antipsychotic side effects.

(7.3) Adolescents/young adults require lower antipsychotic doses.

(7.4) Adolescents/young adults achieve higher rates of remission.

(7.5) Adolescents/young adults should only be treated with antipsychotics that are licensed in that age group.

(7.6) Adolescents/young adults should have fasting metabolic parameters checked more frequently (e.g., 6-monthly).

(7.7) Discontinuation of antipsychotic treatment should be attempted at least once after sufficient time of symptomatic remission and return to premorbid functioning.

(8) During maintenance treatment, the antipsychotic dose should be decreased compared to the effective acute dose.

(10) During antipsychotic treatment of adolescents/young adults with psychosis/EOS, the following side-effects/parameters should be assessed routinely at the following time points:

(10.1) Body weight at least monthly.

(10.2) Blood pressure at least every 3 months.

(10.3) Fasting glucose and lipid parameters at least sixmonthly.

(10.4) Prolactin levels at baseline and target dose during treatment with prolactin-raising antipsychotics.

(10.5) Liver function at least annually.

(10.6) Menstrual dysregulation and sexual dysfunction at each visit during treatment with prolactin-raising antipsychotics.

(10.7) Tardive dyskinesia at least every 3 months.

(10.8) ECG at the time of starting an antipsychotic.

(10.9) ECG at steady dose of antipsychotic treatment.

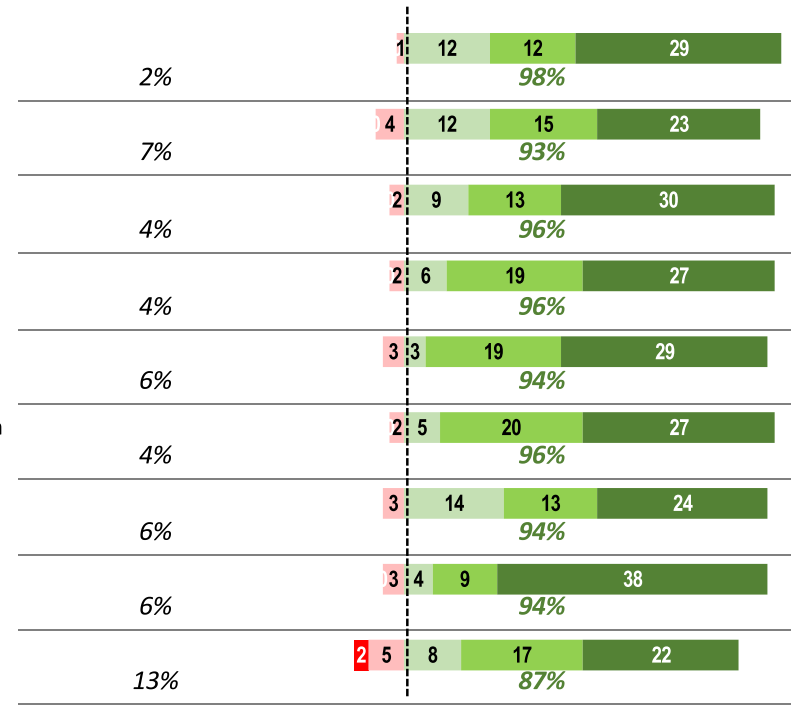

Figure 2 Continued. 


\section{Delphi Round I: Levels of agreement and distribution of responses- Topic 4}

\section{Disagreement}

Agreement

(11) To improve treatment adherence of adolescents/young adults with psychosis/EOS, the following intervention should be used:

(11.1) Building rapport/alliance.

(11.2) Patient psychoeducation

(11.3) Family psychoeducation.

(11.4) Motivational interviewing.

(11.5) Shared decision making.

(11.6) Pill-boxes.

(11.7) Reminders (mail, e-mail, telephone, SMS).

(11.8) Digital interventions (mobile or desktop app).

(11.9) Long-acting injectable antipsychotics.

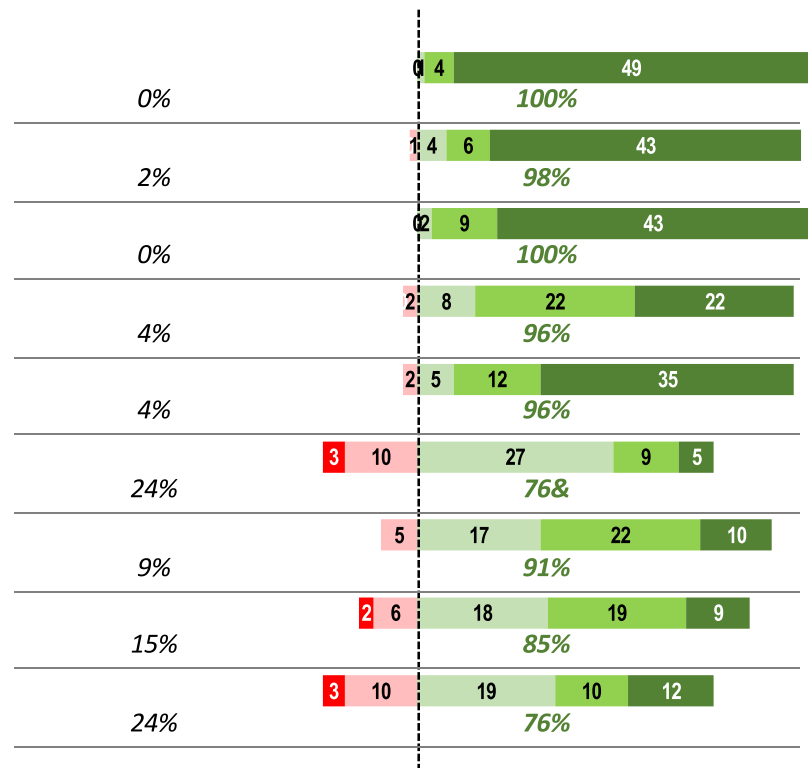

(12) Functional outcome of adolescents/young adults with psychosis/EOS can adequately be improved by:

(12.1) Psychoeducation.

(12.2) Psychodynamic therapy.

(12.3) Cognitive behavioral therapy.

(12.4) Social skills training.

(12.5) Supported employment and education intervention.

(12.6) Occupational therapy.

(12.7) Assertive outreach team.

(12.8) Art / music therapy.

(12.9) Physical activity.

(12.10) Targeting negative symptoms.

(12.11) Targeting cognitive symptoms.

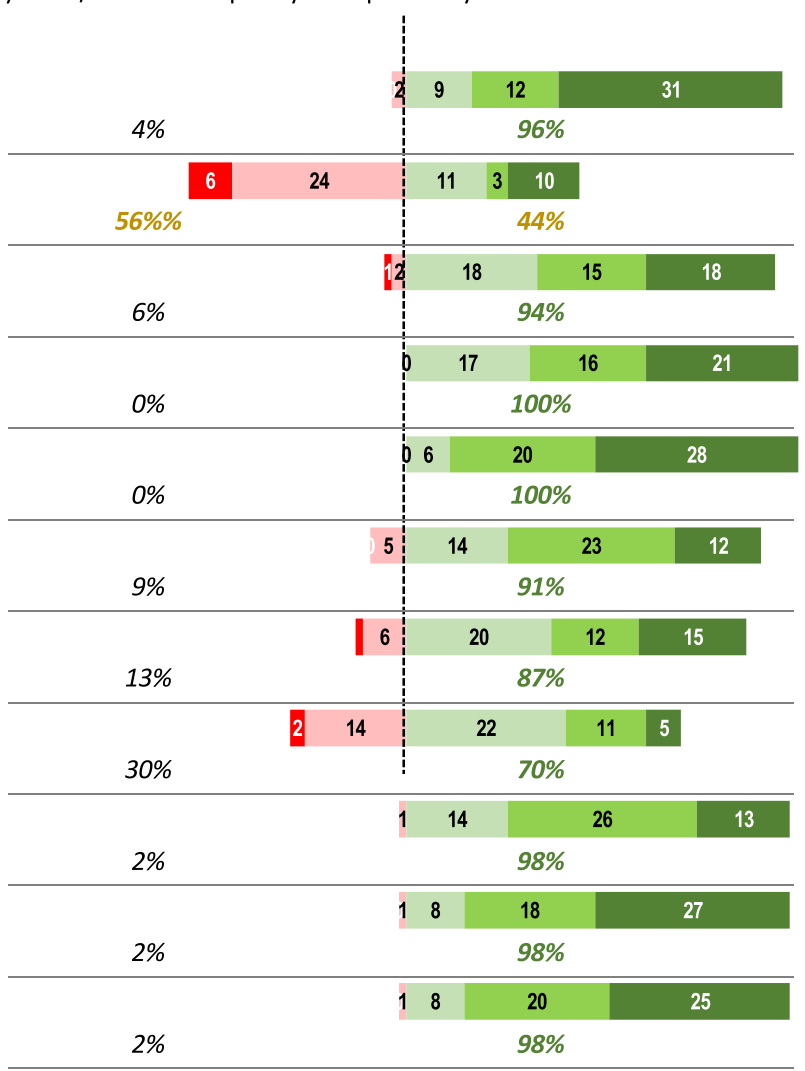

Figure 2 Continued. 


\section{E Delphi Round I: Levels of agreement and distribution of responses- Topic 5}

Disagreement

(13) Local intervention services for adolescents/young adults with early psychosis/EOS should be connected and coordinated within a specialized network.

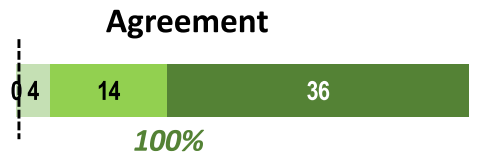

(14) Adolescents/young adults with first episode psychosis should be followed within specialized early intervention services for at least:

(14.1) 6 to less than 12 months.

(14.2) 12 to less than 24 months.

(14.3) 24 months to less than 36 months.

(14.4) 36 months to less than 60 months.

(14.5) 5 years and longer.

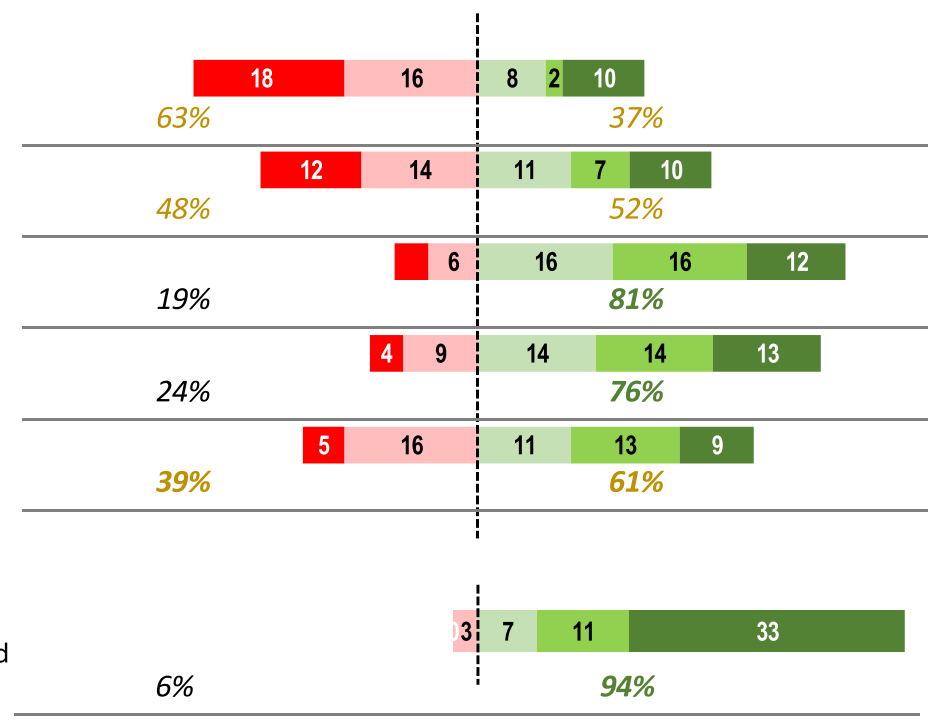

(15) To improve outcomes in patients with psychosis, adolescents/young adults should receive care in an integrated transitional age psychiatric service covering age 15-25.

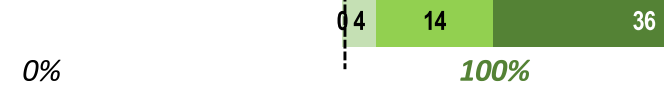

Figure 2 Continued.

after one treatment failure, while most were in favour of switching to clozapine after two and three failures $(70 \%$ and $80 \%$, respectively). However, $20 \%$ of respondents did not agree to the switch even after three treatment failures. Because such a response is in contrast with evidence from the literature, the topic was further explored in the second round by asking which actions the panellists would take instead of clozapine in case of treatment failure. This was explored in Round II through one new statement divided into 4 items (S. 19.1-19.4, Figure 3). While 79\% agreed on adding a psychosocial or psychotherapeutic intervention, no consensus was reached for the proposals of combining two antipsychotics or adding a mood stabilizer, whereas most agreed on not adding ECT (77\% negative consensus).

Finally, as to dosages used in case of suboptimal/nonresponse (S. 18.4), more than half (65\%) disagreed on increasing the dosage above the package insert maximum level, a percentage that increased by $3 \%$ when the question was resubmitted to panellists upon round II.

Tables 1-3 summarize the main scientific evidence concerning the issues above, with the intent of providing some reference to specialists in their decision-making.

\section{Discussion}

We aimed to survey the opinions of European specialists on the main aspects of the management of patients with FEP/ EOS and to explore areas showing a need for some clarification. Overall, panellists' feedback indicated that there is broad agreement on diagnostic standards and on the potential of multimodal approaches, similar to data in adults. ${ }^{38}$ However, opinions varied more widely on pharmacological strategies, treatments to use in cases of failure, and adequate dosing for younger patients. In particular, the responses suggested a careful pharmacological approach, with particular attention to safety aspects.

The mixed responses received on the waiting time before switching to another monotherapy (S. 18) were consistent with many different ranges (from 2-8 weeks) indicated in guidelines ${ }^{44}$ and reflected the lack of uniform definitions for 


\section{F Delphi Round I: Levels of agreement and distribution of responses- Topic 6}

\section{Disagreement}

Agreement

(16) The most important goal of treatment in adolescents/young adults with psychosis is:

(16.1) Symptom remission.

(16.2) Relapse prevention.

(16.3) Functional recovery.

(16.4) Good quality of life.

(16.5) Integrating physical and mental health.

(16.6) Targeting patient goals.

\begin{tabular}{|c|c|c|c|c|}
\hline & 3 & 8 & 18 & 25 \\
\hline \multirow[t]{2}{*}{$6 \%$} & & \multicolumn{3}{|c|}{$94 \%$} \\
\hline & & 3 & 19 & 32 \\
\hline \multirow[t]{2}{*}{$0 \%$} & & \multicolumn{3}{|c|}{$100 \%$} \\
\hline & & 7 & & 45 \\
\hline \multirow[t]{2}{*}{$0 \%$} & 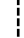 & \multicolumn{3}{|c|}{$100 \%$} \\
\hline & & 13 & & 40 \\
\hline \multirow[t]{2}{*}{$0 \%$} & & \multicolumn{3}{|c|}{$100 \%$} \\
\hline & & 5 & 20 & 29 \\
\hline \multirow[t]{2}{*}{$0 \%$} & & \multicolumn{3}{|c|}{$100 \%$} \\
\hline & & 8 & 15 & 30 \\
\hline $2 \%$ & & \multicolumn{3}{|c|}{$98 \%$} \\
\hline
\end{tabular}

(17) When choosing a first-line antipsychotic in adolescents/young adults, clinicians should consider potential differences in tolerability more than potential differences in efficacy

$9 \%$

\begin{tabular}{l|rrr}
5 & 13 & 22 & 14 \\
\hline & \multicolumn{3}{|c|}{$91 \%$}
\end{tabular}

(18) During antipsychotic treatment of adolescents/young adults with psychosis/EOS the following action should be taken:

(18.1) Change antipsychotic when there is no antipsychotic response after 2 weeks at therapeutic dose.

(18.2) Change antipsychotic when there is no antipsychotic response after 4 weeks at therapeutic dose.

(18.3) Change antipsychotic when there is no antipsychotic response after 6 weeks at therapeutic dose.

(18.4) Increase the antipsychotic dose above package-insert dose levels, in case of antipsychotic non-response.

(18.5) Switch to an antipsychotic monotherapy, in case of antipsychotic non-response.

(18.6) Add a second antipsychotic, in case of antipsychotic non-response.

(18.7) Cross-taper the antipsychotics, when switching antipsychotics.

(18.8) Switch to clozapine, in case of nonresponse to 1 antipsychotic.

(18.9) Switch to clozapine, in case of nonresponse to 2 antipsychotics.

(18.10) Switch to clozapine, in case of nonresponse to 3 antipsychotics.

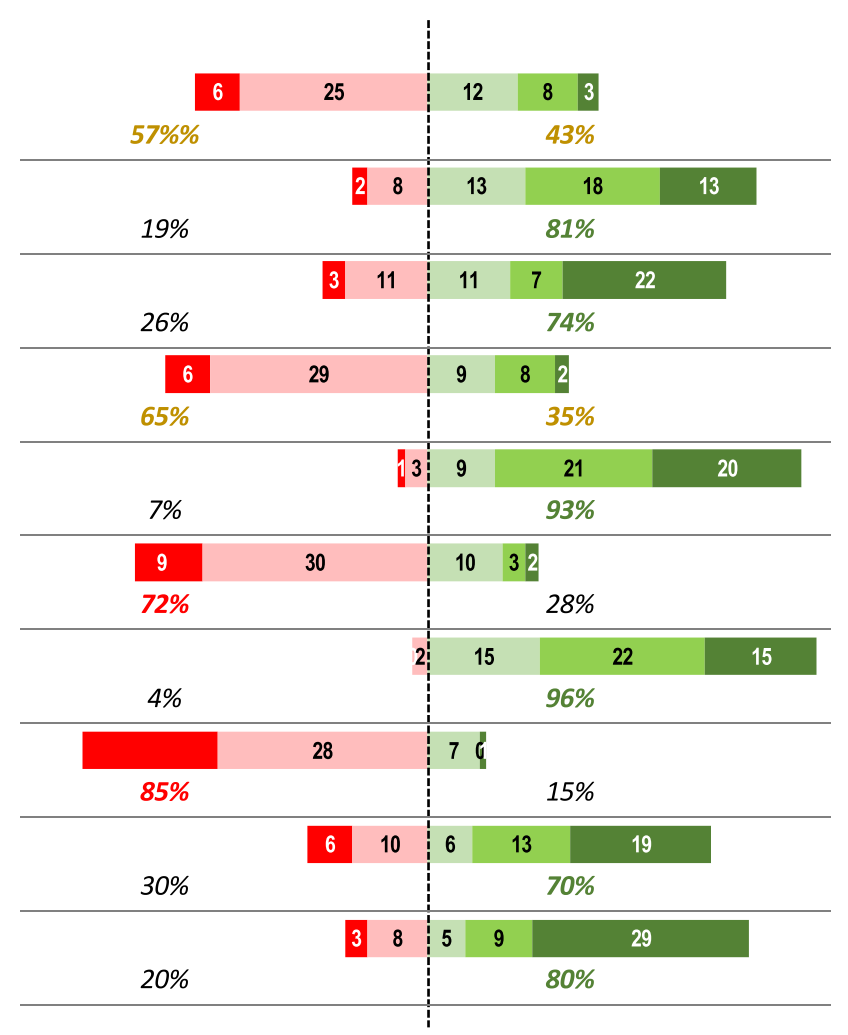

Figure 2 (A) Delphi round I levels of agreement and distribution of responses - Topic I. (B) Delphi round I levels of agreement and distribution of responses - Topic 2. (C) Delphi round I levels of agreement and distribution of responses - Topic 3. (D) Delphi round I levels of agreement and distribution of responses - Topic 4. (E) Delphi round I levels of agreement and distribution of responses - Topic 5. (F) Delphi round I levels of agreement and distribution of responses - Topic 6. 


\section{Topic 1 - Timely detection of signs of psychosis/EOS and formal diagnosis}

Disagreement

(2.7) I would only do a lumbar puncture in case of clinical evidence of a neurological $r$ medical abnormality.

\section{Agreement}

$15 \%$

\begin{tabular}{|l|l|l|l|l|}
\hline 6 & 10 & 12 & & 19 \\
\hline & & & $85 \%$
\end{tabular}

\section{Topic 6 - Clinical Practice/Scientific Evidence}

(18.1) I would continue the specific antipsychotic treatment despite lack of any noticeable symptomatic improvement after one week of treatment with an adequate dose.

(18.2) I would continue the specific antipsychotic treatment despite lack of any noticeable symptomatic improvement after two weeks of treatment with an adequate dose.

(18.3) I would continue the specific antipsychotic treatment despite lack of any noticeable symptomatic improvement after three weeks of treatment with an adequate dose.

(18.4) I would continue the specific antipsychotic treatment despite lack of any noticeable symptomatic improvement after four weeks of treatment with an adequate dose.

(18.5) I would continue the specific antipsychotic treatment despite lack of any noticeable symptomatic improvement after six weeks of treatment with an adequate dose.

18.6) I would increase the antipsychotic dose above packageinsert dose levels, in case of lack of any noticeable symptomatic improvement on that specific antipsychotic taken for an adequate time and dose.

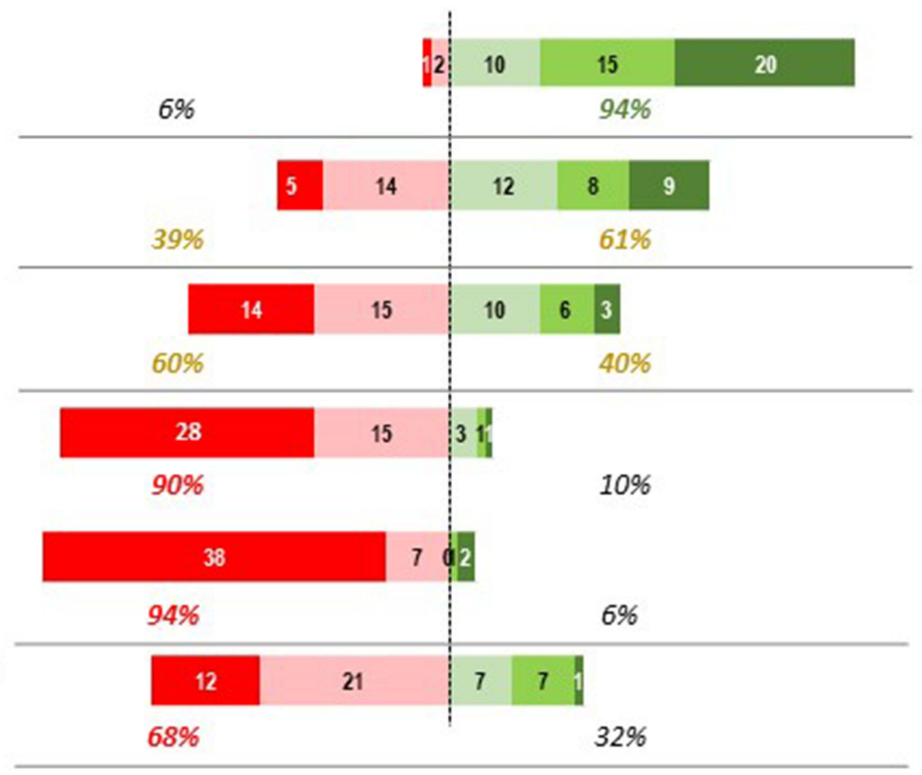

(19) In case of non-response to two antipsychotics at adequate dose and duration, instead of prescribing clozapine as the next step, I would:

(19.1) Combine two antipsychotics

(19.2) Augment with a mood stabilizer

(19.3) Add psychosocial or psychotherapeutic intervention

\begin{tabular}{|c|c|c|c|c|c|}
\hline & 8 & 12 & \multicolumn{2}{|c|}{14} & 113 \\
\hline \multirow[t]{2}{*}{$42 \%$} & & & \multicolumn{3}{|r|}{$58 \%$} \\
\hline & & 18 & & 16 & 92 \\
\hline \multirow[t]{2}{*}{$45 \%$} & & & \multicolumn{3}{|r|}{$55 \%$} \\
\hline & & 9 & 8 & 10 & 20 \\
\hline $21 \%$ & & & \multicolumn{3}{|r|}{$79 \%$} \\
\hline 18 & & 19 & 7 & 4 & \\
\hline $77 \%$ & & & & & $23 \%$ \\
\hline
\end{tabular}

(19.4) Add ECT

Figure 3 Topic I - Timely detection of signs of psychosis/EOS and formal diagnosis. Topic 6 - Clinical practice/scientific evidence.

the concepts of adequate treatment-response time, nonresponse, treatment resistance and response to suboptimal treatment across clinical trials. ${ }^{44}$ However, a diagnostic test meta-analysis ${ }^{45}$ performed on individual patient data showed that patients without even minimal improvement by the second week of antipsychotic treatment are unlikely to improve thereafter. Nevertheless, few data for EOS and first-episode schizophrenia patients are available, and the results are 
Table I Treatment Strategies in Case of Nonresponse to an Antipsychotic Treatment and Evidence from the Literature on Their Appropriateness in EOS

\begin{tabular}{|c|c|c|}
\hline $\begin{array}{l}\text { Treatment } \\
\text { Strategy in Case } \\
\text { of Nonresponse }\end{array}$ & Guidelines/Scientific Evidence & Suggestions Based on Delphi Process Outcome \\
\hline $\begin{array}{l}\text { Increase dose } \\
\text { compared to drug } \\
\text { packaging indications }\end{array}$ & $\begin{array}{l}\text { - No additional benefit from dose-escalation in cases of } \\
\text { initial nonresponse to standard dose therapy }{ }^{46,52} \text { [Dold } \\
2015 \text {; Samara 2018]. } \\
\text { - The antipsychotic can be increased at } 2 \text {-fold or } 3 \text {-fold } \\
\text { MED, as long as closely monitored for side effects }{ }^{54}\end{array}$ & $\begin{array}{l}\text { Make sure therapeutic dose has been reached. If therapy } \\
\text { does not yield response, prefer switch to another } \\
\text { antipsychotic rather than increasing dose. }\end{array}$ \\
\hline $\begin{array}{l}\text { Switch to other } \\
\text { antipsychotic }\end{array}$ & $\begin{array}{l}\text { - Patients who have not even minimally improved by } \\
\text { the second week of antipsychotic treatment are unlikely to } \\
\text { improve later on in the course of treatment } \\
\text { - In the case of two repeated failures over a I2-week } \\
\text { period, perform a thorough investigation of the possible } \\
\text { underlying reasons for nonresponse }\end{array}$ & $\begin{array}{l}\text { The appropriate observation time in which to expect } \\
\text { results is } 2 \text { weeks. In case of nonresponse within this } \\
\text { timeframe, switch to other antipsychotic. }\end{array}$ \\
\hline $\begin{array}{l}\text { Add a second } \\
\text { antipsychotic }\end{array}$ & $\begin{array}{l}\text { - No strong evidence to support gained benefits of } \\
\text { combined therapy. Moreover, the practice raises concerns } \\
\text { for drug-drug interactions and increase of adverse } \\
\text { reactions. }{ }^{49}\end{array}$ & Switch to other antipsychotic. \\
\hline Clozapine & $\begin{array}{l}\text { - Clozapine is effective in both treatment resistant and } \\
\text { non-treatment resistant patients. For some symptoms it is } \\
\text { superior compared to other antipsychotics }{ }^{5,30,35,58,59,61} \\
\text { - Overall } 16 \% \text { occurrence of HAEs (neutropenia and } \\
\text { agranulocytosis) } \\
\text { - Lo } \\
\text { - Only approved drug for treatment-resistant } \\
\text { schizophrenia }^{35} \\
\text { - Before treatment with clozapine, confirm treatment- } \\
\text { refractory schizophrenia' }\end{array}$ & Consider use of clozapine also in younger patients. \\
\hline
\end{tabular}

driven by multiepisode adults with schizophrenia. As further studies explore this timeframe, it is also noteworthy that the Treatment Response and Resistance in Psychosis (TRRIP) Working Group encouraged a more consistent use of the term treatment resistance, ie, referring exclusively to the persistence of significant symptoms, despite adequate treatment in at least two antipsychotic treatment trials lasting 6 weeks each, and during which there was no appreciable symptomatic or functional improvement, as measured by validated rating instruments.

Alternative strategies in the case of nonresponse commonly include a switch to another nonclozapine molecule, antipsychotic dose increase, combination therapy, which generally lacks high-quality evidence, ${ }^{46-49}$ and a switch to clozapine, which has the only clear evidence for efficacy in treatment-resistant schizophrenia. ${ }^{50,51}$

Regarding increasing antipsychotic dosages above the maximum recommended dose in the event of inadequate treatment response, this was addressed by two studies, a meta-analysis and a Cochrane review, ${ }^{46,52}$ which found no additional benefit from dose escalation in cases of initial nonresponse to standard-dose therapy.

More recently, a dose-response meta-analysis investigated the minimum effective dose (MED) and near-maximal and effect size for 20 second-generation antipsychotics. ${ }^{53}$ The study demonstrated that the efficacy of antipsychotics increased proportionally with doses up to the risperidone equivalent of $3-5 \mathrm{mg} / \mathrm{dL}$ and then plateaued. For antipsychotics following an increasing dose-response curve (vs a bell curve), the authors hypothesized that higher-than-licenced doses could be more efficacious. ${ }^{53}$ A subsequent study ${ }^{54}$ of the relationship between 2-fold or 3-fold MED doses and specific side effects confirmed that a dose increase of antipsychotics led to greater differences in terms of side effects rather than 
Table 2 Diagnostic Tools That are Not Considered Standard Practice and Evidence from the Literature on Their Role Within EOS

\begin{tabular}{|c|c|c|}
\hline $\begin{array}{l}\text { Diagnostic } \\
\text { Tool }\end{array}$ & Guidelines/Scientific Evidence & $\begin{array}{l}\text { Suggestions Based on Delphi Process } \\
\text { Outcome }\end{array}$ \\
\hline MRI & $\begin{array}{l}\text { - Magnetic resonance imaging (MRI) brain scanning may be considered in more } \\
\text { complex presentations. }{ }^{2} \\
\text { - MR imaging has emerged as a very powerful tool to map direct } \\
\text { neurobiological processes associated with emerging psychosis. }{ }^{67} \text { An initial MRI } \\
\text { assessment is indicated in early stages of the disorder. }{ }^{67} \\
\text { - MR imaging-based prognostic models for individuals at early stages of } \\
\text { psychosis are not yet ready to be implemented as clinical baseline assessment. }{ }^{67} \\
\text { - When interpreting disease signatures, mechanistically oriented neuroimaging } \\
\text { studies must take nonspecific factors such as antipsychotic drug exposure or } \\
\text { illness chronicity into consideration. }{ }^{68}\end{array}$ & $\begin{array}{l}\text { - If MRI lab available at treatment centre, } \\
\text { perform upon first assessment of early stage. } \\
\text { - If MRI not available, at least perform in cases } \\
\text { of suspicion of organic cause of psychosis. }\end{array}$ \\
\hline EEG & $\begin{array}{l}\text { - Perform EEG for a clinical history suggestive of seizures, which sometimes } \\
\text { resembles schizophrenia. }{ }^{2}\end{array}$ & $\begin{array}{l}\text { - Perform EEG when in presence of a clinical } \\
\text { history suggestive of seizures .... }\end{array}$ \\
\hline $\begin{array}{l}\text { CSF/lumbar } \\
\text { puncture }\end{array}$ & $\begin{array}{l}\text { - Pure psychotic manifestations of antibody-associated autoimmune } \\
\text { encephalitis without any additional neuropsychiatric findings are very rare. } \\
\text { However, special attention must be paid to those presenting with atypical } \\
\text { mental illnesses with additional neurological symptoms. }{ }^{69} \\
\text { - Current findings suggest that schizophrenia and affective disorders may have } \\
\text { CSF abnormalities including signs of blood-brain barrier impairment and } \\
\text { inflammation. However, the available evidence does not allow any firm } \\
\text { conclusion since all studies showed at least some degree of bias and vastly } \\
\text { lacked inclusion of confounding factors. }{ }^{70}\end{array}$ & $\begin{array}{l}\text { - Perform CSF analysis only when there is } \\
\text { clinical evidence of neurological abnormality }\end{array}$ \\
\hline
\end{tabular}

Table 3 Nonpharmacological Treatments Receiving Mixed Feedback and Evidence from the Literature on Their Role Within EOS

\begin{tabular}{|l|l|l|}
\hline $\begin{array}{l}\text { Nonpharmacological } \\
\text { Intervention }\end{array}$ & Guidelines/Scientific Evidence & Suggestions Based on Delphi Process Outcome \\
\hline Dynamic psychotherapy & $\begin{array}{l}\text { It has demonstrated comparable efficacy to other } \\
\text { traditional psychotherapy types, and prolonged benefits } \\
\text { after therapy ends. }\end{array}$ & $\begin{array}{l}\text { Panellists did not consider it useful or that it should be } \\
\text { included into a multimodal approach. Despite scientific } \\
\text { evidence in support being scarce, it has shown to be } \\
\text { effective in clinical practice. }\end{array}$ \\
\hline Supported employment & $\begin{array}{l}\text { Its effectiveness is well-documented; it shows comparable } \\
\text { efficacy to other traditional psychotherapy types and } \\
\text { prolonged benefits after therapy ends. }\end{array}$ & $\begin{array}{l}\text { Strong agreement by panellist supported employment as } \\
\text { being standard intervention. }\end{array}$ \\
\hline
\end{tabular}

efficacy. The authors concluded that while antipsychotic doses can be increased 2- and 3-fold of the MED for increased efficacy, patients should be closely monitored for the emergence of side effects.

Combination therapy is estimated to be quite common in daily clinical practice, occurring in $10-30 \%$ of cases. ${ }^{55}$ However, to date, there is no high-quality evidence from blinded randomized trials to support the benefits of combined therapy ${ }^{51}$ despite some uncontrolled real-world evidence. ${ }^{56,57}$ Because antipsychotic polypharmacy raises concerns about drug-drug interactions and increased adverse reactions, guidelines restrict this strategy to cases in which other treatments, including clozapine, have failed or are impractical, discouraging its use for extended periods of time. ${ }^{2,55}$

Interestingly, while there is little evidence to support the respondents' preference for antipsychotic polypharmacy, there are several lines of evidence to support the use of clozapine. ${ }^{5,33,58-63}$ A network meta-analysis ${ }^{32}$ comparing antipsychotic efficacy and tolerability in children and adolescents measured changes in overall symptoms of schizophrenia, positive and negative symptoms, response, dropouts, quality of life, social functioning and side effects and found 
clozapine to be significantly more effective than all other analysed antipsychotics, although it was associated with significant weight gain. Clozapine's superiority among antipsychotics was also observed in adults (except for negative symptoms), ${ }^{33}$ independent of specific schizophrenia subtypes and degree of treatment resistance. Nonetheless, clozapine appears underused, and the switch to clozapine in our survey gained low support among panellists (20\% would recommend alternative routes even after three treatment failures), likely reflecting the concern about relevant adverse effects with clozapine, ${ }^{64}$ including haematological adverse events (HAEs) and the need for systematic haematological monitoring. ${ }^{1}$ However, HAEs have been relatively low. A study on clozapine-related HAEs in children and adolescents found $13 \%$ of the cases were neutropenia and $0.6 \%$ were agranulocytosis. ${ }^{65}$ These rates are consistent with a subsequent study finding higher rates of mild and moderate neutropenia compared to adults (the majority of which resolved favourably), without cases of agranulocytosis or severe infection. ${ }^{66}$

A major limitation of the study should be acknowledged, that is the small number of expert participants involved. However, to minimize the potential risk for selection bias, panelists were identified according to their long-term experience in the field and on European distribution.

The panel believes that targeted clinical trials are needed to specifically test therapeutic algorithms and the timing of changing medications to treat resistant EOP. Moreover, population-based studies can help provide clinically useful information about the medium- and long-term safety profile of different medications and combinations of medications used under real-world conditions.

\section{Conclusion}

Taken together, responses from panellists reflected a robust consensus of relevant issues in youth and young adults with psychosis/EOS during the vulnerable transitional age regarding diagnostic clues and comprehensive, integrated management. However, uncertainty exists in adapting adult pharmacological approaches to younger age groups while being alert to higher adverse-effect sensitivity of the first-episode/EOS population. Indeed, safety arguments seem to play a major role in the treatment decision-making process. Targeted clinical trials and systematic dissemination across Europe of current scientific evidence on the value of early intervention services also summarized in this Delphi consensus report is hoped to contribute to standardized and improved quality of care for patients with early-phase psychosis and schizophrenia.

\section{Members of the Validation Panel}

Sanja Andric (Serbia), Stefan Jerotic (Serbia), Laura Fusar-Poli (Italy), Maria Nobile (Italy).

\section{Participants in the Delphi Process (Ist Round)}

Olivera Aleksic Hil (Serbia), Celso Arango (Spain), Inmaculada Baeza (Spain), Tobias Banaschewski (Germany), Stefanie Bienioschek (Germany), Ilaria Bonoldi (United Kingdom), Marija Burgic Radmanovic (Bosnia and Herzegovina), Ana Catalan (Spain), Christian Fleischhaker (Germany), Andrea De Micheli (United Kingdom), Covadonga M. Díaz-Caneja (Spain), Montserrat Dolz Abadia (Spain), Richard Drake (United Kingdom), Mauro Ferrara (Italy), Resch Franz (Germany), Eva Gebhardt (Italy), Luca Giorgini (Italy), Montserrat Graell (Spain), Eduardo Iacoponi (United Kingdom), Carlos Imaz Roncero (Spain), Iva Ivanovic (Montenegro), Sonia Johnson (United Kingdom), Leopold Karolina (Germany), Zeljka Kosutic (Serbia), Belinda Lennox (United Kingdom), Stefanie Leopold (Germany), Michael Lipp (Germany), Natasa Ljubomirovic (Serbia), Cloe Llorente Sarabia (Spain), Riccardo Lo Parrino (Italy), Jasminka Markovic (Serbia), Alice Masillo (Italy), Marianne Melau (Denmark), Becker Merle (Germany), Silvia Molteni (Italy), Elena Monducci (Italy), Renata Nacinovich (Italy), Anne Katrine Pagsberg (Denmark), Beatriz Payá (Spain), Milica Pejovic Milovancevic (Serbia), Lorenzo Pelizza (Italy), Danilo Pesic (Serbia), Andrea Pfennig (Germany), Laura Pina-Camacho (Spain), Dorothee Pott (Germany), Matteo Rossi (Italy), Nenad Rudic (Serbia), Stephan Ruhrmann (Germany), Gonzalo Salazar de Pablo (United Kingdom), Sandra Schmalhofer (Germany), Benedetto Vitiello (Italy), Hans Willner (Germany), and Alessandro Zuddas (Italy). 


\section{Participants in the Delphi Process (2nd Round)}

Olivera Aleksic Hil (Serbia), Celso Arango (Spain), Inmaculada Baeza (Spain), Tobias Banaschewski (Germany), Stefanie Bienioschek (Germany), Ilaria Bonoldi (United Kingdom), Marija Burgic Radmanovic (Bosnia and Herzegovina), Ana Catalan (Spain), Christian Fleischhaker (Germany), Andrea De Micheli (United Kingdom), Covadonga M. Díaz-Caneja (Spain), Montserrat Dolz Abadia (Spain), Mauro Ferrara (Italy), Resch Franz (Germany), Eva Gebhardt (Italy), Luca Giorgini (Italy), Montserrat Graell (Spain), Carlos Imaz Roncero (Spain), Iva Ivanovic (Montenegro), Sonia Johnson (United Kingdom), Leopold Karolina (Germany), Zeljka Kosutic (Serbia), Belinda Lennox (United Kingdom), Stefanie Leopold (Germany), Cloe Llorente Sarabia (Spain), Riccardo Lo Parrino (Italy), Jasminka Markovic (Serbia), Alice Masillo (Italy), Marianne Melau (Denmark), Becker Merle (Germany), Silvia Molteni (Italy), Elena Monducci (Italy), Anne Katrine Pagsberg (Denmark), Beatriz Payá (Spain), Milica Pejovic Milovancevic (Serbia), Lorenzo Pelizza (Italy), Danilo Pesic (Serbia), Andrea Pfennig (Germany), Laura Pina-Camacho (Spain), Dorothee Pott (Germany), Nenad Rudic (Serbia), Stephan Ruhrmann (Germany), Gonzalo Salazar de Pablo (United Kingdom), Sandra Schmalhofer (Germany), Benedetto Vitiello (Italy), Hans Willner (Germany), and Alessandro Zuddas (Italy).

\section{Acknowledgments}

The authors wish to thank Ethos srl for logistic support in conducting the Delphi study.

\section{Funding}

The work has been carried out thanks to an unrestricted grant from Angelini Pharma.

\section{Disclosure}

CUC has been a consultant and/or advisor to or has received honoraria from AbbVie, Acadia, Alkermes, Allergan, Angelini, Aristo, Axsome, Cardio Diagnostics, Damitsa, Gedeon Richter, Hikma, Holmusk, IntraCellular Therapies, Janssen/J\&J, Karuna, LB Pharma, Lundbeck, MedAvante-ProPhase, MedInCell, Medscape, Merck, Mindpax, Mitsubishi Tanabe Pharma, Mylan, Neurocrine, Noven, Otsuka, Pfizer, Recordati, Relmada, Rovi, Seqirus, Servier, SK Life Science, Sumitomo Dainippon, Sunovion, Supernus, Takeda, Teva, and Viatris. He provided expert testimony for Janssen and Otsuka. He served on a Data Safety Monitoring Board for Lundbeck, Relmada, Reviva, Rovi, and Teva. He has received grant support from Janssen and Takeda. He received royalties from UpToDate and is also a stock option holder of Cardio Diagnostics, LB Pharma and Mindpax. PFP reports personal fees from Ethos, during the conduct of the study; personal fees from Angelini, Menarini, and Lundbeck, outside the submitted work. SL in the last three years has received honoraria as a consultant and/or advisor and/or for lectures from Alkermes, Angelini, Böhringer Ingelheim, Eisai, Gedeon Richter, Janssen, Johnson and Johnson, Lundbeck, LTS Lohmann, Medichem, Merck Sharpp and Dome, Otsuka, Recordati, Rovi, Sandoz, Sanofi Aventis, Sunovion, and TEVA. AK reports grants and/or personal fees from Janssen-Cilag, Otsuka, Roche, Rovi, Lilly, Lundbeck, outside the submitted work; and is the CEO of Company: MiNDNET e-Health-Solutions GmbH. CM has has received honoraria as a consultant and/or advisor and/or for lectures from Janssen, Angelini, Servier, Nuvelution, Otsuka, Lundbeck, Pfizer, Neuraxpharm, Exeltis, and Esteve. The authors report no other conflicts of interest in this work.

\section{References}

1. McClellan J, Stock S. American Academy of Child and Adolescent Psychiatry (AACAP) Committee on Quality Issues (CQI). Practice parameter for the assessment and treatment of children and adolescents with Schizophrenia. J Am Acad Child Adolesc Psychiatry. 2013;52:976-990. doi:10.1016/j. jaac.2013.02.008

2. Surveillance report 2016 - psychosis and schizophrenia in children and young people: recognition and management (2013) NICE guideline CG155. Available from: https://www.nice.org.uk/guidance/cg155/resources/surveillance-report-2016-psychosis-and-schizophrenia-in-children-and-youngpeople-recognition-and-management-2013-nice-guideline-cg155-2674146925/chapter/Surveillance-decision. Accessed January 15, 2022.

3. Hasan A, Falkai P, Wobrock T, et al. World Federation of Societies of Biological Psychiatry (WFSBP) Guidelines for biological treatment of schizophrenia, Part 1: update 2012 on the acute treatment of schizophrenia and the management of treatment resistance. World J Biol Psychiatry. 2012;13:318-378. doi:10.3109/15622975.2012.696143

4. International Early Psychosis Association Writing Group. International clinical practice guidelines for early psychosis. Br J Psychiatry Suppl. 2005;48:s120-124. doi:10.1192/bjp.187.48.s120 
5. Galletly C, Castle D, Dark F, et al. Royal Australian and New Zealand College of psychiatrists clinical practice guidelines for the management of schizophrenia and related disorders. Aust N Z J Psychiatry. 2016;50:410-472. doi:10.1177/0004867416641195

6. Rund BR. The research evidence for schizophrenia as a neurodevelopmental disorder. Scand J Psychol. 2018;59:49-58. doi:10.1111/sjop.12414

7. Newton R, Rouleau A, Nylander AG, et al. Diverse definitions of the early course of schizophrenia-A targeted literature review. NPJ Schizophr. 2018;4:21. doi:10.1038/s41537-018-0063-7

8. Masi G, Liboni F. Management of schizophrenia in children and adolescents: focus on pharmacotherapy. Drugs. 2011;71:179-208. doi:10.2165/ 11585350-000000000-00000

9. Simeone JC, Ward AJ, Rotella P, Collins J, Windisch R. An evaluation of variation in published estimates of schizophrenia prevalence from 1990-2013: a systematic literature review. BMC Psychiatry. 2015;15:193. doi:10.1186/s12888-015-0578-7

10. Solmi M, Radua J, Olivola M, et al. Age at onset of mental disorders worldwide: large-scale meta-analysis of 192 epidemiological studies. Mol Psychiatry. 2021. doi:10.1038/s41380-021-01161-7

11. Hayes D, Kyriakopoulos M. Dilemmas in the treatment of early-onset first-episode psychosis. Ther Adv Psychopharmacol. 2018;8:231-239. doi:10.1177/2045125318765725

12. Stentebjerg-Olesen M, Pagsberg AK, Fink-Jensen A, Correll CU, Jeppesen P. Clinical characteristics and predictors of outcome of schizophrenia-spectrum psychosis in children and adolescents: a systematic review. J Child Adolesc Psychopharmacol. 2016;26:410-427. doi:10.1089/cap.2015.0097

13. Raballo A, Poletti M. Advances in early identification of children and adolescents at risk for psychiatric illness. Curr Opin Psychiatry. 2020;33:611-617. doi:10.1097/YCO.0000000000000652

14. Fusar-Poli P, Salazar de Pablo G, Correll CU, et al. Prevention of psychosis: advances in detection, prognosis, and interveNTION. JAMA Psychiatry. 2020;77:755-765. doi:10.1001/jamapsychiatry.2019.4779

15. American Psychiatric Association. Diagnostic and statistical manual of mental disorders (DSM-5); 2013.

16. De Berardis D, De Filippis S, Masi G, et al. A neurodevelopment approach for a transitional model of early onset schizophrenia. Brain Sci. 2021;11:275. doi:10.3390/brainsci11020275

17. Jaaro-Peled H, Sawa A. Neurodevelopmental factors in schizophrenia. Psychiatr Clin N Am. 2020;43:263-274. doi:10.1016/j.psc.2020.02.010

18. Baribeau DA, Anagnostou E. A comparison of neuroimaging findings in childhood onset schizophrenia and autism spectrum disorder: a review of the literature. Front Psychiatry. 2013;4:175. doi:10.3389/fpsyt.2013.00175

19. Boksa P. Abnormal synaptic pruning in schizophrenia: Urban myth or reality? J Psychiatry Neurosci. 2012;37:75-77. doi:10.1503/jpn.120007

20. Schultze-Lutter F, Schimmelmann BG. Early detection and treatment of psychosis: the Bern child and adolescent psychiatric perspective. Adv Psychiatry. 2014;2014:365283. doi:10.1155/2014/365283

21. Davies C, Segre G, Estradé A, et al. Prenatal and perinatal risk and protective factors for psychosis: a systematic review and meta-analysis. Lancet Psychiatry. 2020;7:399-410. doi:10.1016/S2215-0366(20)30057-2

22. Griffa A, Baumann PS, Klauser P, et al. Brain connectivity alterations in early psychosis: from clinical to neuroimaging staging. Transl Psychiatry. 2019;9:62. doi:10.1038/s41398-019-0392-y

23. Arango C, Dragioti E, Solmi M, et al. Risk and protective factors for mental disorders beyond genetics: an evidence-based atlas. World Psychiatry. 2021;20:417-436. doi:10.1002/wps.20894

24. Raballo A, Poletti M, Preti A, et al. Clinical high risk for psychosis in children and adolescents: a meta-analysis of transition prevalences. Schizophr Res. 2020;S0920-9964(20)30174-2. doi:10.1016/j.schres.2020.03.063

25. Kendhari J, Shankar R, Young-Walker L. A review of childhood-onset schizophrenia. Focus. 2016;14:328-332. doi:10.1176/appi.focus.20160007

26. Raballo A, Poletti M. Childhood schizotypal features vs. high-functioning autism spectrum disorder: developmental overlaps and phenomenological differences. Schizophr Res. 2020;223:53-58. doi:10.1016/j.schres.2020.09.027

27. Carrion R, Correll C, Auther A, et al. A severity-based clinical staging model for the psychosis prodrome: longitudinal findings from the new york recognition and prevention program. Schizophr Bull. 2017;43:64-74. doi:10.1093/schbul/sbw155

28. Lutgens D, Gariepy G, Malla A. Psychological and psychosocial interventions for negative symptoms in psychosis: systematic review and meta-analysis. Br J Psychiatry. 2017;210:324-332. doi:10.1192/bjp.bp.116.197103

29. Mayer-Amberg N, Woltmann R, Walther S. An integrated care initiative to improve patient outcome in schizophrenia. Front Psychiatry. 2016;6:184. doi:10.3389/fpsyt.2015.00184

30. Correll CU. Antipsychotic use in children and adolescents: minimizing adverse effects to maximize outcomes. J Am Acad Child Adolesc Psychiatry. 2008;47:9-20. doi:10.1097/chi.0b013e31815b5cb1

31. Arango C, Ng-Mak D, Finn E, et al. Lurasidone compared to other atypical antipsychotic monotherapies for adolescent schizophrenia: a systematic literature review and network meta-analysis. Eur Child Adolesc Psychiatry. 2020;29:1195-1205. doi:10.1007/s00787-019-01425-2

32. Krause M, Zhu Y, Huhn M, et al. Efficacy, acceptability, and tolerability of antipsychotics in children and adolescents with schizophrenia: a network meta-analysis. Eur Neuropsychopharmacol. 2018;28:659-674. doi:10.1016/j.euroneuro.2018.03.008

33. Pagsberg AK, Tarp S, Glintborg D, et al. Acute antipsychotic treatment of children and adolescents with schizophrenia-spectrum disorders: a systematic review and network meta-analysis. $J$ Am Acad Child Adolesc Psychiatry. 2017;56:191-202.

34. Solmi M, Fornaro M, Ostinelli EG, et al. Safety of 80 antidepressants, antipsychotics, anti-attention-deficit/hyperactivity medications and mood stabilizers in children and adolescents with psychiatric disorders: a large scale systematic meta-review of 78 adverse effects. World Psychiatry. 2020;19:214-232. doi:10.1002/wps.20765

35. EMEA/CPMP/6034/02/en/Final. Committee for Proprietary Medicinal Products (CPMP) summary information on referral opinion following arbitration pursuant to article 30 of council directive 2001/83/EC For Leponex and associated names. International NonProprietary Name (INN): clozapine. Available from: https://www.ema.europa.eu/en/documents/referral/summary-information-referral-opinion-following-arbitration-pursuant -article-30-council-directive/83/ec-leponex-associated-names-international-non-proprietary-name-inn-clozapine-background-inform_en.pdf. Accessed January 15, 2022.

36. Zhu Y, Krause M, Huhn M, et al. Antipsychotic drugs for the acute treatment of patients with a first episode of schizophrenia: a systematic review with pairwise and network meta-analyses. Lancet Psychiatry. 2017;4:694-705. doi:10.1016/S2215-0366(17)30270-5

37. Huhn M, Nikolakopoulou A, Schneider-Thoma J, et al. Comparative efficacy and tolerability of 32 oral antipsychotics for the acute treatment of adults with multi-episode schizophrenia: a systematic review and network meta-analysis. Lancet. 2019;394:939-951. doi:10.1016/S0140-6736(19)31135-3 
38. Correll CU, Galling B, Pawar A, et al. Comparison of early intervention services vs treatment as usual for early-phase psychosis a systematic review, meta-analysis, and meta-regression. JAMA Psychiatry. 2018;75:555-565. doi:10.1001/jamapsychiatry.2018.0623

39. Pringsheim T, Kelly M, Urness D, et al. Physical health and drug safety in individuals with schizophrenia. Can J Psychiatry. 2017;62:673-683. doi: $10.1177 / 0706743717719898$

40. Braddick F, Carral V, Jenkins R, et al. Child and Adolescent Mental Health in Europe (CAMHEE): infrastructures, policy and programmes. Luxembourg: European Communities; 2009.

41. Coppens E, Vermet I, Knaepes J, et al. Adolescent mental health care in Europe: state of the art, recommendations, and guidelines by the ADOCARE* network. Brussels; 2015. Available from: http://www.adocare.eu/wp-content/uploads/2015/12/Adolescent-mental-health-care-inEurope-state-of-the-art-recommendations-and-guidelines.pdf. Accessed January 15, 2022.

42. Jorm AF. Using the Delphi expert consensus method in mental health research. Aust $N Z J$ Psychiatry. 2015;49:887-897. doi:10.1177/ 0004867415600891

43. Hasson F, Keeney S, McKenna H. Research guidelines for the Delphi survey technique. J Adv Nurs. 2000;32:1008-1015.

44. Howes OD, McCutcheon R, Agid O, et al. Treatment-resistant schizophrenia: Treatment Response and Resistance in Psychosis (TRRIP) Working group consensus guidelines on diagnosis and terminology. Am J Psychiatry. 2017;174:216-229. doi:10.1176/appi.ajp.2016.16050503

45. Samara MT, Leucht C, Leeflang MM, et al. Early improvement as a predictor of later response to antipsychotics in schizophrenia: a diagnostic test review. Am J Psychiatry. 2015;172:617-629. doi:10.1176/appi.ajp.2015.14101329

46. Samara MT, Klupp E, Helfer B, et al. Increasing antipsychotic dose for non response in schizophrenia. Cochrane Database Syst Rev. 2018;5: CD011883.

47. Correll CU, Rubio JM, Inczedy-Farkas G, et al. Efficacy of 42 pharmacologic cotreatment strategies added to antipsychotic monotherapy in schizophrenia: systematic overview and quality appraisal of the meta-analytic evidence. JAMA Psychiatry. 2017;74:675-684. doi:10.1001/ jamapsychiatry.2017.0624

48. Correll CU, Brevig T, Brain C. Exploration of treatment-resistant schizophrenia subtypes based on a survey of 204 US psychiatrists. Neuropsychiatr Dis Treat. 2019;15:3461-3473. doi:10.2147/NDT.S234813

49. Galling B, Roldán A, Hagi K, et al. Antipsychotic augmentation vs. monotherapy in schizophrenia: systematic review, meta-analysis and meta-regression analysis. World Psychiatry. 2017;16:77-89. doi:10.1002/wps.20387

50. Siskind D, Siskind V, Kisely S. Clozapine response rates among people with treatment-resistant schizophrenia: data from a systematic review and meta-analysis. Can J Psychiatry. 2017;62:772-777. doi:10.1177/0706743717718167

51. Siskind D, McCartney L, Goldschlager R, et al. Clozapine v. first- and second-generation antipsychotics in treatment-refractory schizophrenia: systematic review and meta-analysis. Br J Psychiatry. 2016;209:385-392. doi:10.1192/bjp.bp.115.177261

52. Dold M, Fugger G, Aigner M, et al. Dose escalation of anti- psychotic drugs in schizophrenia: a meta-analysis of randomized controlled trials. Schizophr Res. 2015;166:187-193. doi:10.1016/j.schres.2015.04.024

53. Leucht S, Crippa A, Siafis S, et al. Dose-response meta-analysis of antipsychotic drugs for acute schizophrenia. Am J Psychiatry. 2020;177:342-353. doi:10.1176/appi.ajp.2019.19010034

54. Takeuchi H, MacKenzie NE, Samaroo D, et al. Antipsychotic dose in acute schizophrenia: a meta-analysis. Schizophr Bull. 2020;46:1439-1458. doi:10.1093/schbul/sbaa063

55. Gallego JA, Bonetti J, Zhang J, et al. Prevalence and correlates of antipsychotic polypharmacy: a systematic review and meta-regression of global and regional trends from the 1970s to 2009. Schizophr Res. 2012;138:18-28. doi:10.1016/j.schres.2012.03.018

56. Tiihonen J, Taipale H, Mehtälä J, et al. Association of antipsychotic polypharmacy vs monotherapy with psychiatric rehospitalization among adults with schizophrenia. JAMA Psychiatry. 2019;76:499-507. doi:10.1001/jamapsychiatry.2018.4320

57. Guinart D, Correll CU. Antipsychotic polypharmacy in schizophrenia: Why not? J Clin Psychiatry. 2020;81:19ac13118. doi:10.4088/JCP.19ac13118

58. Stepnicki P, Kondej M, Kaczor A. Current concepts and treatments of schizophrenia. Molecules. 2018;23:2087. doi:10.3390/molecules23082087

59. Smart SE, Kępińska A, Murray RM, et al. Predictors of treatment-resistant schizophrenia: a systematic review of prospective observational studies. Psychol Med. 2021;51:44-53. doi:10.1017/S0033291719002083

60. Schneider C, Corrigall R, Hayes D, et al. Systematic review of the efficacy and tolerability of clozapine in the treatment of youth with early onset schizophrenia. Eur Psychiatry. 2014;29:1-10. doi:10.1016/j.eurpsy.2013.08.001

61. Schneider C, Papachristou E, Wimberley T, et al. Clozapine use in childhood and adolescent schizophrenia: a nationwide population-based study. Eur Neuropsychopharmacol. 2015;25:857-863. doi:10.1016/j.euroneuro.2015.02.003

62. Samara MT, Dold M, Gianatsi M, et al. Efficacy, acceptability, and tolerability of antipsychotics in treatment-resistant schizophrenia: a network meta-analysis. JAMA Psychiatry. 2016;73:199-210. doi:10.1001/jamapsychiatry.2015.2955

63. Leon J, Ruand CJ, Schoretsanitisf G, et al. A rational use of clozapine based on adverse drug reactions, pharmacokinetics, and clinical pharmacopsychology. Psychother Psychosom. 2020;89:200-214. doi:10.1159/000507638

64. Nielsen J, Correll CU, Manu P, et al. Termination of clozapine treatment due to medical reasons: when is it warranted and how can it be avoided? J Clin Psychiatry. 2013;74:603-613; quiz 613. doi:10.4088/JCP.12r08064

65. Gerbino-Rosen G, Roofeh D, Tompkins DA, et al. Hematological adverse events in clozapine-treated children and adolescents. $J$ Am Acad Child Adolesc Psychiatry. 2005;44:1024-1031. doi:10.1097/01.chi.0000171904.23947.54

66. Maher KN, Tan M, Tossell JW, et al. Risk factors for neutropenia in clozapine-treated children and adolescents with childhood-onset schizophrenia. J Child Adolesc Psychopharmacol. 2013;23:110-116. doi:10.1089/cap.2011.0136

67. Schmidt A, Borgwardt S. Implementing MR imaging into clinical routine screening in patients with psychosis? Neuroimaging Clin N Am. 2020;30 (1):65-72. doi:10.1016/j.nic.2019.09.004

68. Kraguljac NV, McDonald WM, Widge AS, Rodriguez CI, Tohen M, Nemeroff CB. Neuroimaging biomarkers in schizophrenia. Am J Psychiatry. 2021;178(6):509-521. doi:10.1176/appi.ajp.2020.20030340

69. Bien CG, Rohleder C, Mueller JK, Bien CI, Koethe D, Leweke FM. Neural autoantibodies in cerebrospinal fluid and serum in clinical high risk for psychosis, first-episode psychosis, and healthy volunteers. Front Psychiatry. 2021;26(12):654602. doi:10.3389/ fpsyt.2021.654602

70. Orlovska-Waast S, Köhler-Forsberg O, Brix SW, et al. Cerebrospinal fluid markers of inflammation and infections in schizophrenia and affective disorders: a systematic review and meta-analysis. Mol Psychiatry. 2019;24(6):869-887. doi:10.1038/s41380-018-0220-4 
71. Shedler J. The efficacy of psychodynamic psychotherapy. Am Psychol. 2010;65(2):98-109. doi:10.1037/a0018378

72. Marino LA, Dixon LB. An update on supported employment for people with severe mental illness. Curr Opin Psychiatry. 2014;27(3):210-215. doi:10.1097/YCO.0000000000000058

\section{Publish your work in this journal}

Neuropsychiatric Disease and Treatment is an international, peer-reviewed journal of clinical therapeutics and pharmacology focusing on concise rapid reporting of clinical or pre-clinical studies on a range of neuropsychiatric and neurological disorders. This journal is indexed on PubMed Central, the 'PsycINFO' database and CAS, and is the official journal of The International Neuropsychiatric Association (INA). The manuscript management system is completely online and includes a very quick and fair peer-review system, which is all easy to use. Visit http://www.dovepress.com/testimonials.php to read real quotes from published authors.

Submit your manuscript here: https://www.dovepress.com/neuropsychiatric-disease-and-treatment-journal 